\title{
Influence of Quasi-Steady Wind Loads on the Fatigue Damage of Wind Turbine Gearboxes
}

\author{
Dong Xiang* - Li Jiang - Mengxing You - Yinhua Shen \\ Tsinghua University, Department of Mechanical Engineering, China
}

Quasi-steady wind varies both in time and space and has a great influence on a wind turbine gearbox's fatigue life. Quasi-steady wind fields are described by mean wind speed and turbulence intensity, and the influence of these two parameters on wind turbine gearbox's fatigue life is studied. Based on the two-step decoupled method (the first step is global analysis and the second is gearbox dynamic analysis), a model which can calculate the complex gearbox's fatigue damage from gear's dynamic force and SN parameters is established. The fatigue damage of every gear calculated from the established model is then analysed. The fatigue damage result under certain wind loads is first analysed, and the vulnerable gears among each stage are found. Then, how mean wind speed and turbulence intensity influences fatigue damage is studied, and the damage comparison factors are calculated, which finds the $3^{\text {rd }}$ stage pinion to be the gear most sensitive to wind loads, and it requires more attention when designing gearboxes. Finally, the gears' fatigue damage sensitivities to mean wind speed and turbulence intensity are analysed and the condition in which fatigue damage is more sensitive to wind loads is found, this is meaningful when designing pitch control systems.

Keywords: quasi-steady wind load, fatigue life, wind turbine gearbox, LDD, FAST, ADAMS

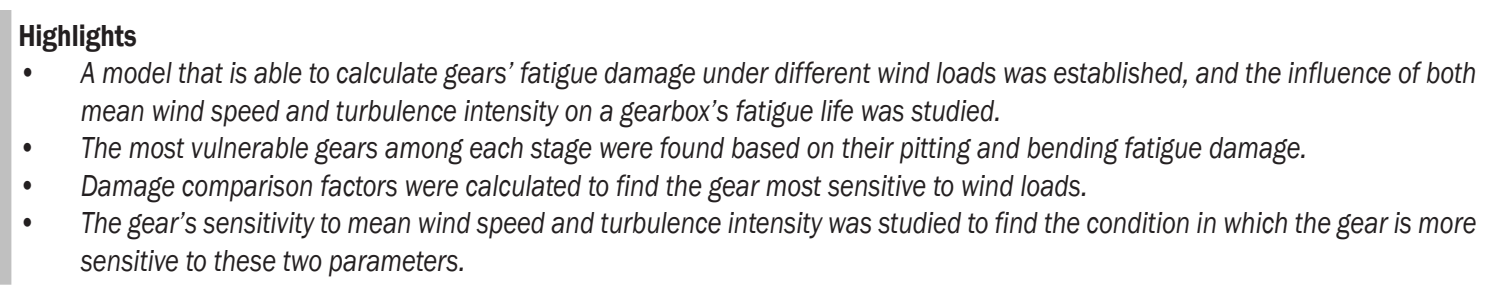

\section{INTRODUCTION}

Wind turbines translate wind energy into electrical energy, but because wind speed varies both in time and space and over a wide variety of ranges, wind energy has more variability compared to other energy source, such as solar energy. Wind turbines frequently experience premature gearbox failures, and they are responsible for the majority of wind turbine operational downtime [1]. At the same time, the wind speed's fluctuation has a great impact on gearbox's dynamic loads. Thus, it is paramount to know how wind loads influence wind turbine gearbox's fatigue damage, especially when designing a wind turbine gearbox.

Quasi-steady wind is wind turbine's input and has a great impact on its behaviour, and the influence has been studied by many scholars. Rosen and Sheinman [2] studied turbulence's effects on wind turbine's mean power, and exhibits the great influence of wind turbulent dynamic effects on wind turbine's mean output power. Sheinman and Rosen [3] presented a new method to predict the influence of wind turbulence on the energy produced by a wind turbine and concluded that power may be over predicted by $10 \%$ if the influence of turbulence is neglected.

The gearbox's dynamic load is a main factor influencing its fatigue life and it has been studied by many researchers. To acquire a gearbox's operational condition, a wind turbine global analysis should be done first. Jin et al. [4] proposed a blade-cabin-towerfoundation-coupled model to study the influence of seismic load on wind turbine dynamic responses. Nejad et al. [5] uses an aero-servo-hydrodynamic analysis tool to obtain forces, moments and angular velocities of the gearbox for wind turbines with different platforms. Many other researchers [5] to [11] use FAST code to acquire a gearbox's operational condition.

To obtain gearbox dynamic response under certain operational conditions, gearbox dynamic modelling should be conducted. $\mathrm{Xu}$ et al. [12] developed a dynamic model that integrates the gearbox body flexible supporting stiffness to study the effect of gearbox body flexibility on dynamic responses, and the result shows that dynamic transmission error and mesh force is lowered by considering body flexibility. Ajmi and Velex [13] proposed a dynamic model aimed at simulating the quasi-static and dynamic behaviour 


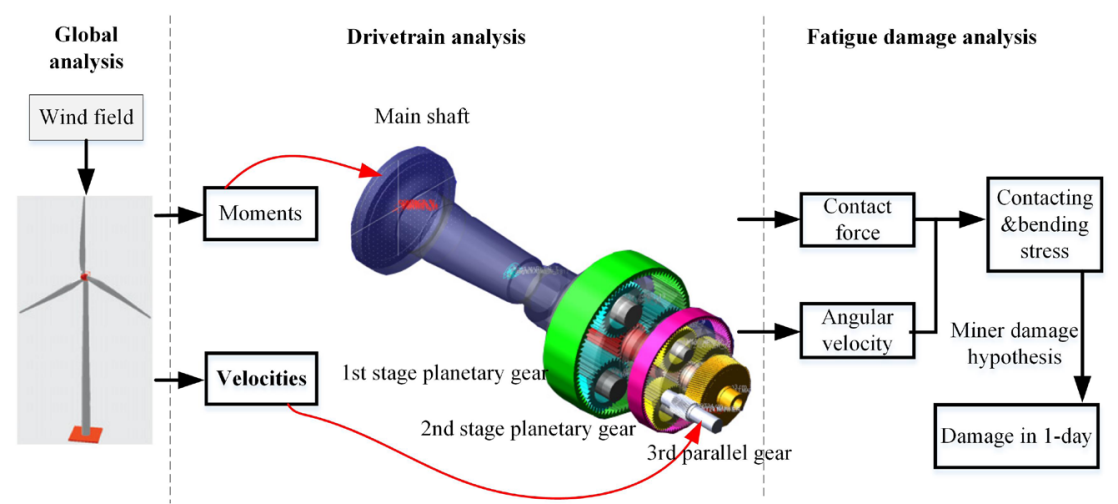

Fig. 1. Process of calculating gearbox's fatigue damage

of solid wide-faced gears. Osman and Velex [14] studied the interactions between contact fatigue damage and dynamic tooth loads, and the result shows that gear's contact fatigue clearly depends on dynamic phenomena. Oyague [6] introduced a twostep decoupled method to obtain gearbox's dynamic response which use FAST to get global response and SIMPACK to obtaining gearbox's dynamic response. Micallef and Sant [7] used SIMPACK to model wind turbine gearbox and used the model to study the load effects on a floating offshore horizontal axis wind turbine on surge motion. Nejad et al. [8] used both numerical and experimental methods to study the effects of floating sun gear and concluded that for errorless gears, the non-floating sun gear design performs better, while for gearbox with planet misalignment, the floating sun gear design performs better. Nejad et al. [9] established a gearbox model in SIMPACK to study the influence of mean wind speed on a wind turbine gearbox's fatigue life.

None of the above researchers studied the joint influence of mean wind speed and turbulence on a wind turbine gearbox's fatigue damage. In this paper, both the effect of these two parameters are analysed by calculating every gear's pitting and bending fatigue damage under different quasi-steady wind fields. The quasi-steady wind field is separated into two groups: NTM (normal turbulence model) and ETM (extreme turbulence model), and the fatigue damage is calculated for both these two groups using the fatigue damage calculation model established in this paper.

\section{METHODS}

Fig. 1 shows the details of the process of analysing wind turbine gearbox's fatigue damage, and three analysis steps are used. The first step is a global analysis which takes the quasi-steady wind field as the input and calculates gearbox's inputs and outputs. The Second step is drivetrain analysis, in which the moments and velocities acquired from the global analysis are applied to the dynamic model in ADAMS so that the dynamic loads and speeds of each gear can be obtained. The first two steps are called the "decoupled analysis method", which is also used in reference [5], [8] to [11]. The third step is fatigue damage analysis; in this step, the dynamic loads are first translated into stress bins based on the load duration distribution (LDD) method [9], and then fatigue damage is calculated from stress bins and the gear's SN parameters. The details are described as follows.

\subsection{Global Analysis}

Global analysis is intended to obtain the gearbox's inputs and outputs under different quasi-steady wind fields, and mean wind speed and turbulence intensity are the two chosen parameters influencing gearbox's fatigue damage. In this study, the quasi-steady wind field, which is the input to the global analysis, was generated according to the Kaimal spectrum [15] by TurbSim [16], using $20 \times 20$ points in the rotor plane with time step $0.02 \mathrm{~s}$. Both the normal turbulence model (NTM) and extreme turbulence model (ETM) [17] were used to generate different wind fields. The range of mean wind speed is $5 \mathrm{~m} / \mathrm{s}$ to $20 \mathrm{~m} / \mathrm{s}$ with an increment of $2 \mathrm{~m} / \mathrm{s}$, and the turbulence intensity ranges from $9 \%$ to $24 \%$ with an increment of $2 \%$, the global responses of each wind speed with different turbulence intensities were obtained.

Wind turbine global simulations were conducted using the FAST code provided by NREL, which can model the dynamic responses of horizontal-axis wind turbines (HAWTs) under aerodynamic load effects [7]. The wind turbine in this study is designed by a 
company in China; the general description of the turbine is listed in Table 1. The main characteristics of the global analysis model are described as follows. The wind turbine is fixed to the ground, and the blade and tower are modelled as two-degree-freedom bodies. The main shaft is modelled as a torsional spring and damper, and the main parameters of the drivetrain is listed in Table 2. The blade pitch control is modified using a PI gain scheduling controller [18], and constant torque strategy is used. The integral coefficient KI and proportional coefficient KP are listed in Table 3. The outputs of global analysis, including torque on the main shaft and angular speed of the generator shaft, are shown in Fig. 2 when the mean wind speed is $11.5 \mathrm{~m} / \mathrm{s}$ and turbulence is $14 \%$.

Table 1. General description of the wind turbine

\begin{tabular}{lc}
\hline Type & Three blade up wind \\
\hline Power rating & $1.5 \mathrm{MW}$ \\
\hline Rotor diameter & $70 \mathrm{~m}$ \\
\hline Rated rotor speed & $17.5 \mathrm{rpm}$ \\
\hline Tower & Welded tabular steel \\
\hline Hub height & $80 \mathrm{~m}$ \\
\hline Cut-in wind speed & $3 \mathrm{~m} / \mathrm{s}$ \\
\hline Cut-out wind speed & $25 \mathrm{~m} / \mathrm{s}$ \\
\hline Rated wind speed & $11.5 \mathrm{~m} / \mathrm{s}$ \\
\hline Design wind class & $\mathrm{IEC} \mathrm{III}$ \\
\hline Design life & 20 years \\
\hline
\end{tabular}

Table 2. Drivetrain's main parameters

\begin{tabular}{lc}
\hline parameter & value \\
\hline main shaft stiffness & $5 \mathrm{e} 9 \mathrm{~N} \cdot \mathrm{m} / \mathrm{rad}$ \\
\hline main shaft damping ratio & $1 \mathrm{e} 7 \mathrm{~N} \cdot \mathrm{m} / \mathrm{s}$ \\
\hline rotor inertial & $3.0854 \mathrm{e} 6 \mathrm{~kg} \cdot \mathrm{m}^{2}$ \\
\hline generator inertial & $53.036 \mathrm{~kg} \cdot \mathrm{m}^{2}$ \\
\hline Gearbox ratio & 100.75 \\
\hline
\end{tabular}

Table 3. Pitch control system's parameters

\begin{tabular}{lcc}
\hline coefficient & $\mathrm{KP}$ & $\mathrm{Kl}$ \\
\hline value & 0.033498 & 0.0089128 \\
\hline
\end{tabular}

The rotor's torque and power determine the gearbox's behaviour, and their mean values and standard deviations under different wind fields are shown in Figs. 3 and 4, respectively. As presented in Fig. 3, the mean power is almost equal for different turbulence intensities. The mean power increases very fast when the wind speed is lower than the rated wind speed and stays constant (almost $1650 \mathrm{~kW}$ ) when wind speed is higher. The power's standard deviation rises with the turbulence intensity, which is easy to understand. The rotor's mean torque curve, shown in Fig. 4, follows almost the same trend as the power curve, as does the standard torque deviation. All the results above which show the same regularity with the previously published result [11] can ensure the normal operation of global analysis. Since global analysis results are the inputs and outputs of drivetrain analysis, the normal operation of the global analysis can make the drivetrain analysis more reliable.

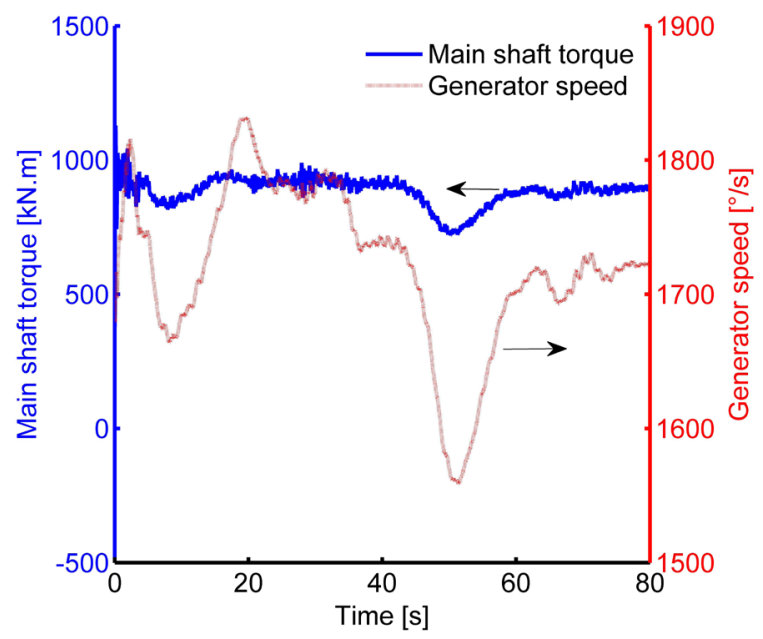

Fig. 2. Outputs of global analysis

\subsection{Gearbox Drivetrain Analysis}

To calculate every gear's fatigue damage, the dynamic loads and speeds of each gear should be obtained. Multi-body dynamic analysis software is used to calculate every gear's dynamic loads and speeds. The reference gearbox that is used in a $1.5 \mathrm{MW}$ wind turbine was modelled in ADAMS, as shown in Fig. 1. The reference gearbox's schematic layout is shown in Fig. 5, it consists of three stages; the first two stages are planetary gears ( 3 planets), and the third stage is a parallel gear. All the components in the gearbox were modelled as rigid bodies, which are interconnected by joints and force elements. The topology diagram of the model is shown in Fig. 6. The contact force element was used to model the gear contact force. In ADAMS, the contact force is calculated using the impact function [19]. For the gearbox used in this study, whose parameter is shown in Table 4, the stiffness of each contact force element is calculated according to the Hertz theory, the force exponent is chosen to be 1.5 , and the damping term is 0.1 percent of the stiffness [19], the main parameters of all contact force elements are shown in Table 5.

As shown in Fig. 1, the moment obtained from the global analysis was loaded on the main shaft, and 
the speed of the high-speed shaft was controlled to follow the speed obtained from the global analysis.

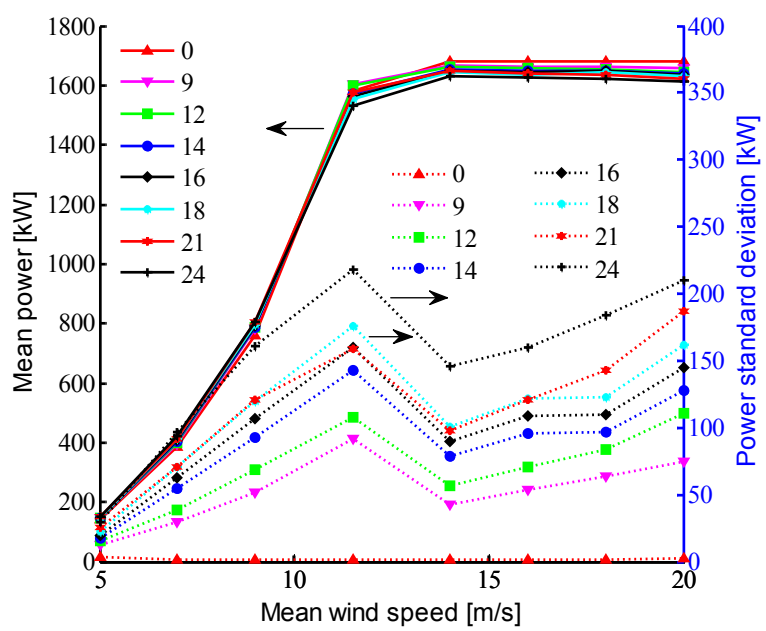

Fig. 3. Mean and standard deviation of rotor's power

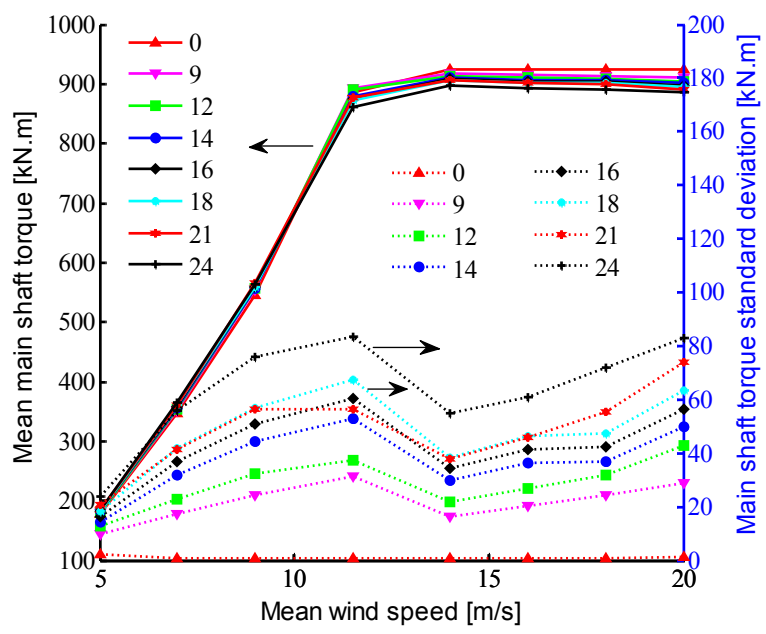

Fig. 4. Mean and standard deviation of rotor's torque

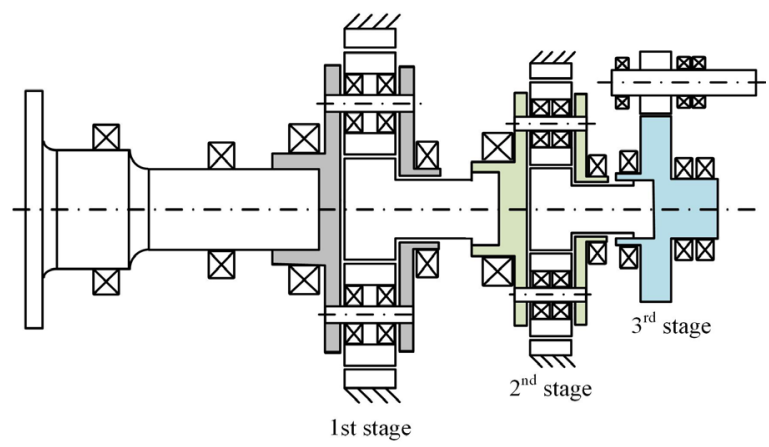

Fig. 5. Reference gearbox schematic layout

The simulation is carried out for $80 \mathrm{~s}$ with time step size to be $0.001 \mathrm{~s}$, and GSTIFF-SI2 was used as the dynamics integration solver. The first $20 \mathrm{~s}$ of the results were discarded to avoid numerical convergence uncertainties, and the effect of the unsteady response when the wind turbine starts up. The contact force of each meshing gear was collected from the simulation result which is used in the next fatigue damage analysis part. The first stage of the sun gear's contact force, when mean wind speed is 11.5 $\mathrm{m} / \mathrm{s}$ and turbulence intensity is $14 \%$, is shown in Fig. 7 as an example.

Table 4. Gear parameters

\begin{tabular}{|c|c|c|c|c|c|c|c|}
\hline & & $z$ & $M[\mathrm{~mm}]$ & $\alpha_{n}\left[^{\circ}\right]$ & $\beta\left[^{\circ}\right]$ & $x$ & $b[\mathrm{~mm}]$ \\
\hline \multirow{3}{*}{ 1st } & $\mathrm{s}$ & 23 & \multirow{3}{*}{14} & \multirow{3}{*}{20} & \multirow{3}{*}{0} & 0.46 & 380 \\
\hline & $p$ & 34 & & & & 0.48 & 380 \\
\hline & $r$ & 91 & & & & -1.42 & 370 \\
\hline \multirow{3}{*}{ 2nd } & $\mathrm{s}$ & 25 & \multirow{3}{*}{ 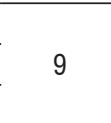 } & \multirow{3}{*}{20} & \multirow{3}{*}{0} & 0.28 & 180 \\
\hline & $p$ & 45 & & & & 0.31 & 180 \\
\hline & $r$ & 116 & & & & -0.36 & 170 \\
\hline \multirow{2}{*}{$3 r d$} & $p$ & 28 & \multirow{2}{*}{6} & \multirow{2}{*}{20} & \multirow{2}{*}{12} & 0.08 & 190 \\
\hline & $\mathrm{G}$ & 101 & & & & 0.15 & 180 \\
\hline
\end{tabular}

$z=$ number of teeth; $M=$ normal module; $\beta=$ helix angle;

$x=$ modification coefficient; $b=$ face width

Table 5. Parameters of contact force elements

\begin{tabular}{lccccc}
\hline & \multicolumn{2}{c}{1 st } & \multicolumn{2}{c}{$2^{\text {nd }}$} & \multirow{2}{*}{ 3rd } \\
\cline { 1 - 5 } & s-p & $p-r$ & s-p & p-r & \\
\hline Stiffness $[\mathrm{kN} / \mathrm{m}]$ & $9.6 \mathrm{e} 5$ & $1.3 \mathrm{e} 6$ & $8 \mathrm{e} 5$ & $1.1 \mathrm{e} 6$ & $8 \mathrm{e} 5$ \\
\hline Force exponent & 1.5 & 1.5 & 1.5 & 1.5 & 1.5 \\
\hline Damping $[\mathrm{kN} \cdot \mathrm{s} / \mathrm{m}]$ & 900 & 1200 & 800 & 1100 & 800 \\
\hline Penetration depth $[\mathrm{mm}]$ & 0.1 & 0.1 & 0.1 & 0.1 & 0.1 \\
\cline { 1 - 4 }
\end{tabular}

$s-p=$ contact force element between sun and planet gear $p-r=$ contact force element between planet and ring gear

\subsection{Fatigue Damage Analysis}

The purpose of fatigue damage analysis is to calculate gears' pitting and bending fatigue damage from the obtained contact force. To calculate the gears' fatigue damage, two things need to be done: one is to translate the time-domain contact force into stress bins and another is every gear's pitting and bending $\mathrm{SN}$ curves (SN curve is given as $N \cdot \sigma m=K$, where $\sigma$ is the maximum stress, $K$ and $m$ are defined as SN parameters).

The acquired contacting forces were first separated into a number of bins using the LDD method and the cycles for each force bin were calculated using Eq. (1) [9]. Next, the bending and contacting stress bins can be obtained using root bending [20] and flank contacting [21] stress calculation equations, Eqs. (2)and (3), respectively. From stress bins, the 


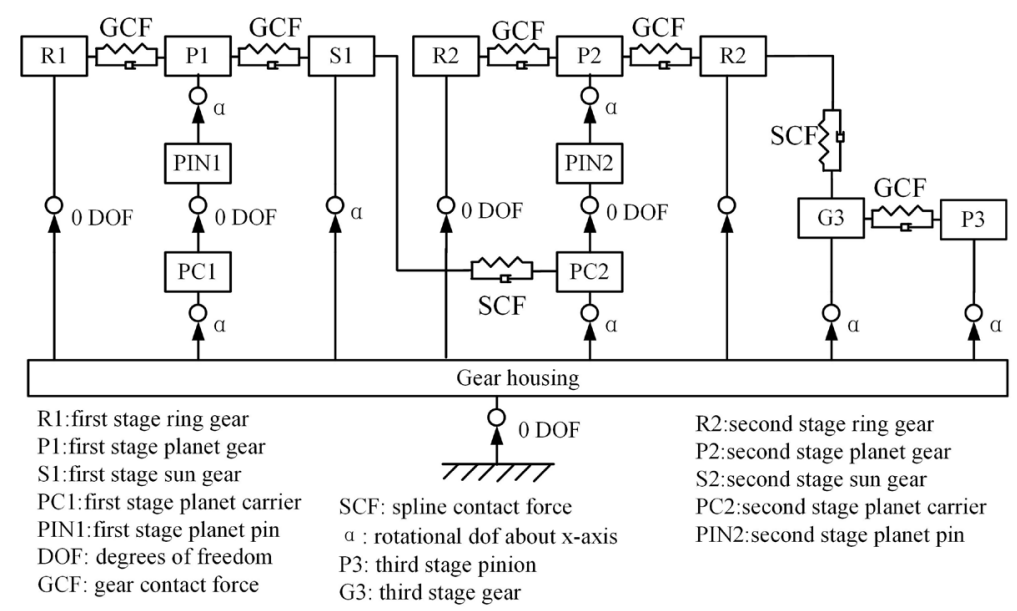

Fig. 6. Topology diagram of ADAMS' gearbox model

bending and contacting stress cycle at each stress level is known which is used to calculate gear's fatigue damage.

$$
n_{i}=\sum \frac{t_{j} \omega_{j}}{2 \pi}
$$

where $n_{i}$ is the number of stress cycles of force bin $i ; t_{j}$ is one part of the time duration of force bin $i ; \omega_{j}$ is the mean angular velocity of gear during $t_{j}$ in $\mathrm{rad} / \mathrm{s}$.

$$
\sigma_{F}=\frac{F_{t}}{b m_{n}} Y_{F} Y_{S} Y_{\beta} Y_{B} Y_{D T},
$$

where $F_{t}$ is the gear contact force; $b$ is the gear face width; $m_{n}$ is the normal module; $Y_{F}, Y_{S}, Y_{\beta}, Y_{B}$ and $Y_{D T}$ are the factors considering the influence of tooth form, load application, helix angle, rim thickness and contact ratio, respectively.

$$
\sigma_{H}=Z_{H} Z_{E} Z_{\varepsilon} Z_{\beta} \sqrt{\frac{F_{t}}{b d_{1}} \frac{u+1}{u}},
$$

where $d_{1}$ is the reference diameter; $u$ is the gear ratio; $Z_{H}, Z_{E}, Z_{\varepsilon}$ and $Z_{\beta}$ are the zone factor, elasticity factor, contact ratio factor, and helix angle factor, respectively.

The SN parameters were calculated from ISO 6336-2 [21], ISO 6336-3 [20] and ISO 6336-5 [22] whose fatigue data is obtained from endurance fatigue tests of reference gears. Material and heat treatment are two factors influencing gear's SN parameters, and for the studied gearbox, all gears' material is case carburized $18 \mathrm{CrNiMo} 7-6$ except the first and second stage's ring gear whose material is through hardened 34CrNiMo6 (note that every gear has different $\mathrm{SN}$ parameters). To calculate fatigue damage more precisely, a two-slope SN curve is used with the second slope to be $1 /(2 \mathrm{~m}-1)$.

After acquiring stress bins and SN parameters, the bending and pitting fatigue damages were calculated according to the Palgren-Miner linear damage hypothesis:

$$
D_{c}=\sum_{i=1}^{N_{b}} \frac{n_{i}}{N_{c i}}
$$

where $N_{b}$ is the total number of stress bins; $n_{i}$ is the stress cycles of stress bin $i ; N_{c i}$ is the number of stress cycles leading to fatigue failure which is calculated from the $\mathrm{SN}$ curve; $D_{c}$ is the cumulative fatigue damage.

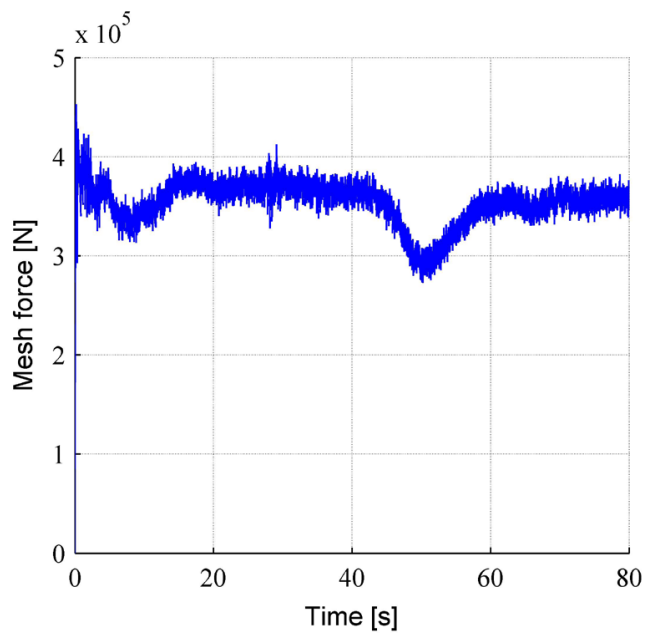

Fig. 7. First stage sun gear's contact force

The pitting and bending fatigue damage of each gear within one day were calculated (assuming that every minute's damage in one day is the same). A 
gear tooth goes in and out in every rotation so that the bending and contacting stress ranges from zero to the peak value, or in other words, the stress ratio $R=0$. While the planetary gear is special since its forward- and back-flank are all loaded when meshing so that the planetary gear's bending stress ranges from minus peak value to peak value which means $R \approx-1$ [20]. Since there are three planets in every planetary gear train, the sun and ring gear's load cycle numbers should be multiplied by 3 . From the description above, it is clear that using stress bins and SN parameters to calculate gear's fatigue damage is easy and the cumulative effect of meshing force on gear is quantified, which can be used to analyse the influence of quasi-steady wind loads or other factors on gearbox's fatigue behaviour. The calculated fatigue damage cannot only be used to compute gear's fatigue life, but also be used to compare every gear's fatigue behaviour.

Fig. 8 shows the comparison between the first stage of the sun gear's bending fatigue damage caused by NTM and ETM wind model with the mean wind speed ranges from $5 \mathrm{~m} / \mathrm{s}$ to $20 \mathrm{~m} / \mathrm{s}$ and turbulence intensity ranges from $12 \%$ to $16 \%$. It can be observed that the damages caused by these two wind models are almost the same. Based on this conclusion, we can know that it is reasonable to only use the NTM wind model to study the effect of wind loads on gearbox's fatigue life. This phenomenon may be caused by the wind turbine's pitch control, since when the speed is beyond rated, the pitch angle is controlled so that constant input torque is acquired.

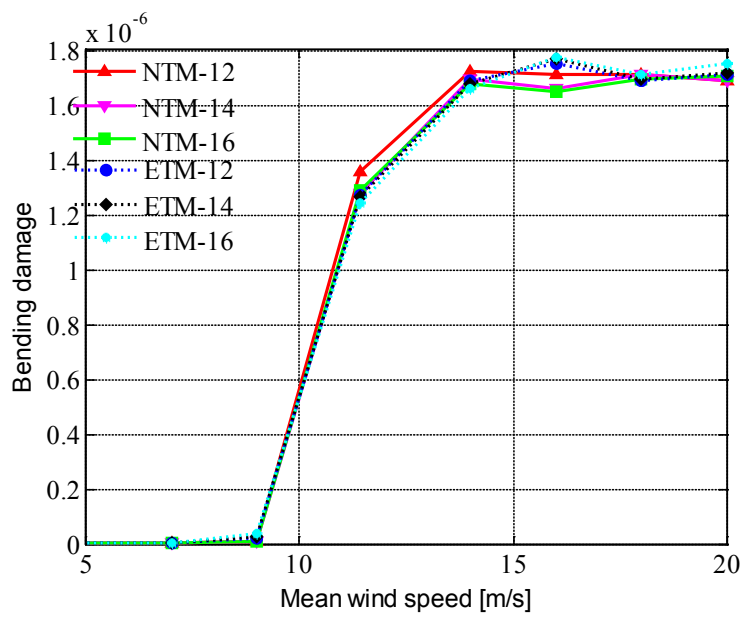

Fig. 8. Comparison of first stage sun gear's bending fatigue damage between ETM \& NTM

\section{RESULTS AND DISCUSSION}

The bending and pitting fatigue damages of every gear under different quasi-steady wind loads are calculated using the above method; in this part, the fatigue damage results are presented and analysed to determine how mean wind speed and turbulence intensity influence gears' fatigue damage. The results are provided in the following order:

- To find the most vulnerable gears among each stage, fatigue damage under certain wind load is analysed.

- The fatigue damage analysis result under different wind loads section is dedicated to study the influence of quasi-steady wind loads on the fatigue damage of each gear.

\subsection{Fatigue Damage Analysis Result under Certain Wind Loads}

From the fatigue damage results under one or two certain wind loads, it is found that a most vulnerable component exists among each stage which has the highest fatigue damage, and the component with higher fatigue damage has a higher probability of fatigue failure. It is very useful to find the components with a higher probability of fatigue failure among each stage, which can be used in the following analysis and give the advantage of detecting the source of failure.

Table 6. 1-day tooth bending \& flank pitting fatigue damage

\begin{tabular}{|c|c|c|c|c|c|}
\hline \multirow{2}{*}{\multicolumn{2}{|c|}{ gear }} & \multicolumn{2}{|c|}{$11.5 \mathrm{~m} / \mathrm{s}$} & \multicolumn{2}{|c|}{$18 \mathrm{~m} / \mathrm{s}$} \\
\hline & & $\begin{array}{c}D_{b} \\
\left(\times 10^{-6}\right)\end{array}$ & $\begin{array}{c}D_{p} \\
\left(\times 10^{-6}\right) \\
\end{array}$ & $\begin{array}{c}D_{b} \\
\left(\times 10^{-6}\right) \\
\end{array}$ & $\begin{array}{c}D_{p} \\
\left(\times 10^{-6}\right) \\
\end{array}$ \\
\hline \multirow{4}{*}{1 st } & sun & 1.28 & 483 & 1.71 & 603.0 \\
\hline & planet-forwarda & \multirow{2}{*}{88.2} & 109 & \multirow{2}{*}{113.0} & 136.1 \\
\hline & planet-backa & & 0.003 & & 0.003 \\
\hline & ring & 437.6 & 0.2 & 548.3 & 0.269 \\
\hline \multirow{4}{*}{$2^{\text {nd }}$} & sun & 0.051 & 38.5 & 0.072 & 48.42 \\
\hline & planet-forwarda & \multirow{2}{*}{77.0} & 7.13 & \multirow{2}{*}{97.6} & 8.97 \\
\hline & planet-backa & & - & & - \\
\hline & ring & 155.7 & - & 193.3 & - \\
\hline \multirow{2}{*}{3 rd } & gear & 0.596 & 0.010 & 1.023 & 0.014 \\
\hline & pinion & 9.20 & 0.035 & 14.7 & 0.048 \\
\hline
\end{tabular}

a Planet gear contacts with sun gear in the forward flank and ring gear in the back, so pitting fatigues are separated into forward- and back-pitting damage; "-" value is too small to display; $D_{b}=$ bending damage; $D_{p}=$ pitting damage.

The 1-day tooth bending fatigue damage at wind speed $11.5 \mathrm{~m} / \mathrm{s}$ (rated wind speed) and $18 \mathrm{~m} / \mathrm{s}$ with turbulence intensity to be $14 \%$ is shown in Fig. 9 and 


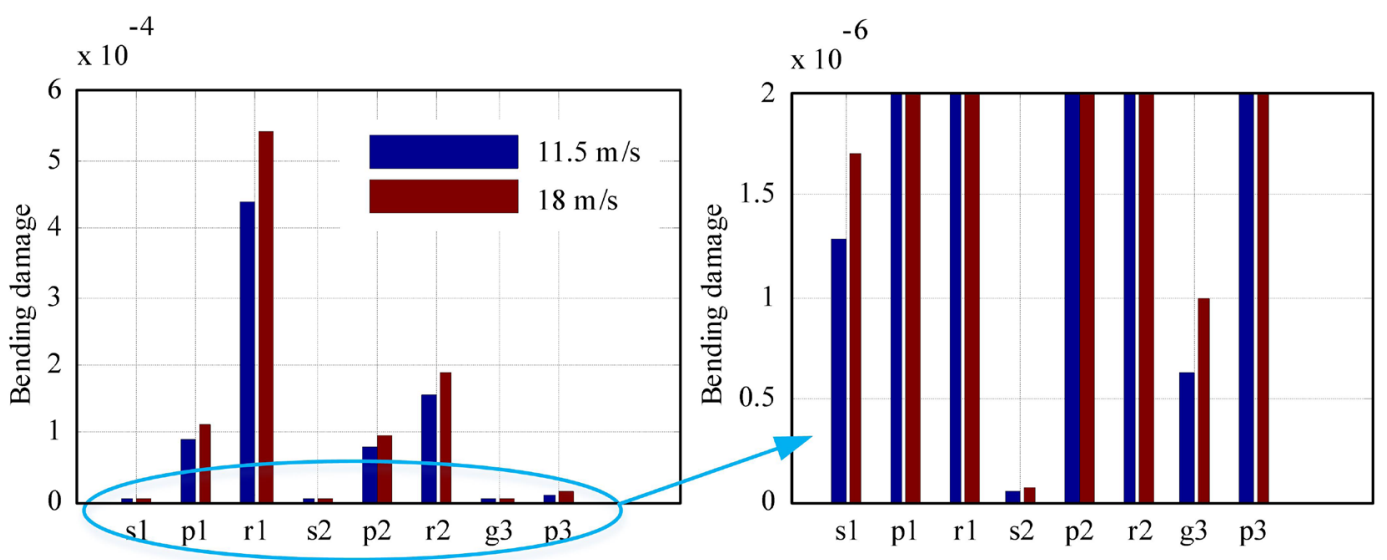

Fig. 9. 1-day gear tooth bending fatigue damage (s1 = first stage sun; $p 1$ = first stage planet; $r 1$ = first stage ring; s2 = second stage sun; p2 = second stage planet; $r 2$ = second stage ring; $p 3$ = third stage pinion; $g 3$ = third stage gear)

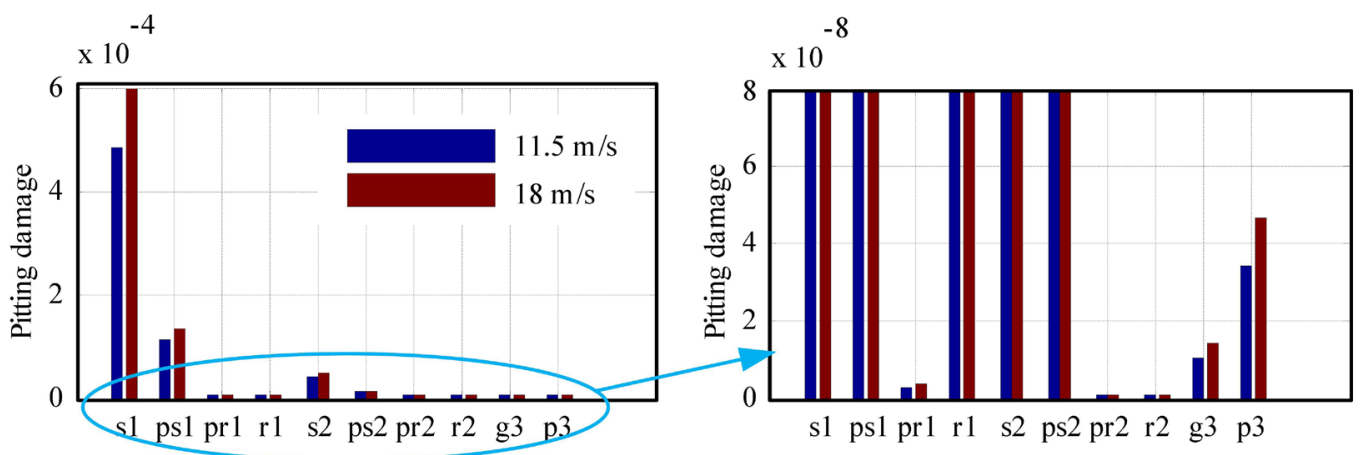

Fig. 10. 1-day gear tooth pitting fatigue damage (s1 = first stage sun; $r 1$ = first stage ring; $p s 1$ = first stage planet's pitting damage caused by s1; pr1 = first stage planet's pitting damage caused by r1; $s 2$ = second stage sun; $r 2$ = second stage ring; ps2 = second stage planet's pitting damage caused by s2; pr2 = second stage planet's pitting damage caused by r2; $\mathrm{p} 3$ = third stage pinion; g3 = third stage gear)

Table 6. The first and second stage's ring gear and third stage's pinion are found to be the components with the highest bending fatigue damage. The reason for the first and second stages' ring gear lies in the material properties since $18 \mathrm{CrNiMo7}-6$ has higher nominal bending stress values $\left(\sigma_{\text {Flim }}\right)$. The fatigue damage result in [23] shows sun gear to be the most vulnerable gear among the first stage, which is caused by the higher number of load cycles, while every gear has its own SN parameters considering its material, heat treatment, tooth shape, etc., so that the number of load cycles cannot determine fatigue damage. The material for ring and sun gears are through hardened 34CrNiMo6 and carburized 18CrNiMo7-6, respectively. The gear made of through hardened 34CrNiMo6 shows a lower life limit compared with 18CrNiMo7-6 at the same bending stress level, so that the ring gear would result higher bending fatigue damage even with lower number of load cycles. In contrast, for the third stage, [23] also claim that pinion is more vulnerable, this is because pinion and gear share the same material and manufacturing which result almost the same SN parameters so that higher number of cycles would result higher fatigue damage.

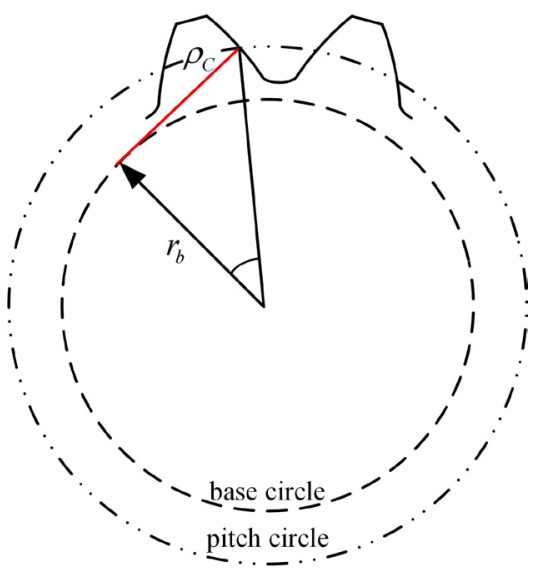

Fig. 11. Definition of radius of relative curvature at the pitch surface 
Table 6 and Fig. 10 show the calculated 1-day flank pitting fatigue damage. The first and second stages' sun gear and third stage's pinion show higher pitting fatigue damage among each stage. The smaller radius of relative curvature at the pitch surface $\left(\rho_{C}\right.$, see Fig. 11 for the definition) of the sun gear and a higher number of cycles cause the higher pitting fatigue damage of the first and second stage's sun gear. Third stage's pinion shows higher pitting fatigue damage than gear because of its higher number of cycles. The large radius of relative curvature at the pitch surface of ring gears caused small contacting stress which results in small pitting fatigue damage. From the result, the planet-backward pitting fatigue damage is much lower
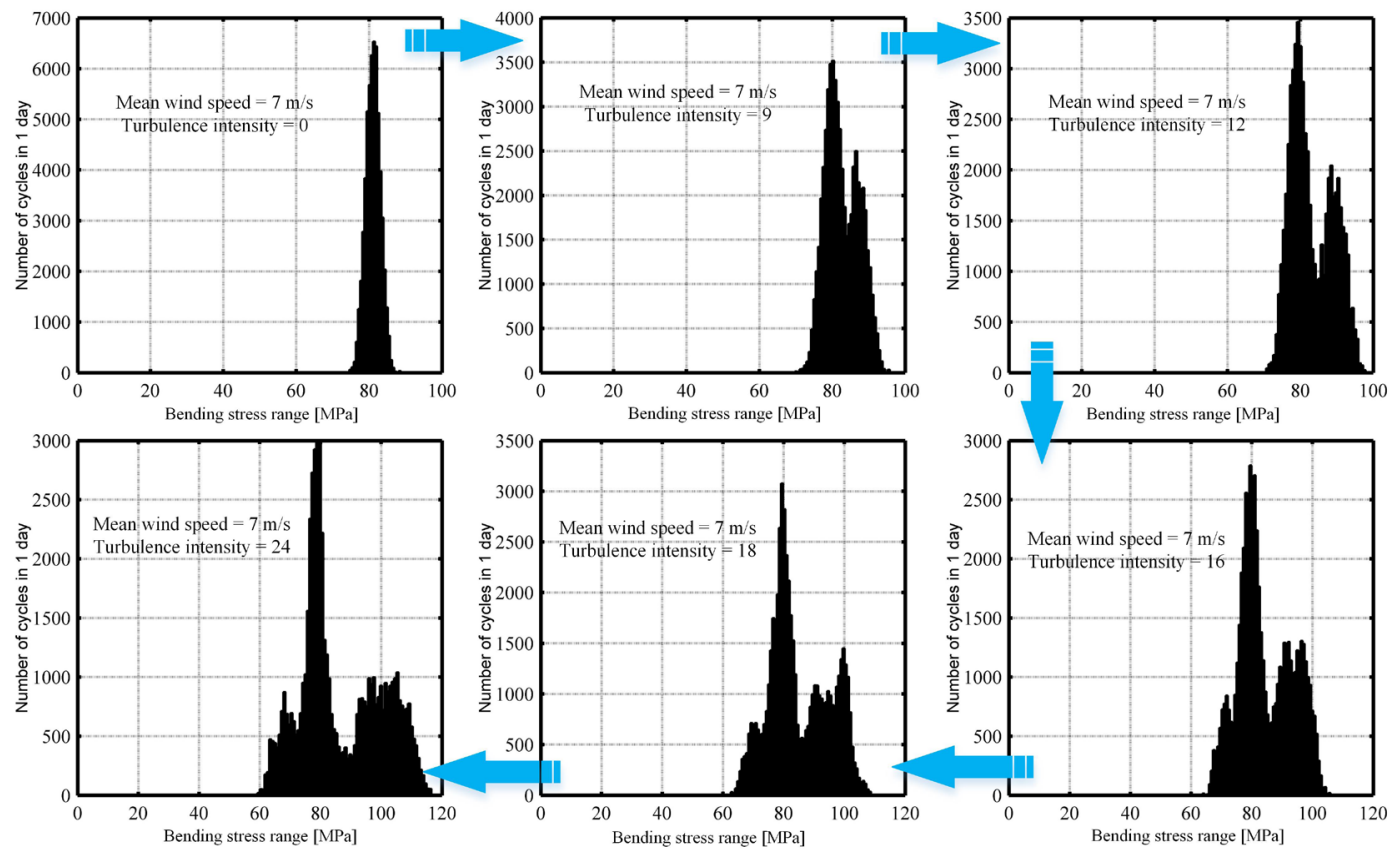

Fig. 12. Bending stress bins of the first stage sun gear when mean wind speed is $7 \mathrm{~m} / \mathrm{s}$ and turbulence intensity ranges from $0 \%$ to $24 \%$
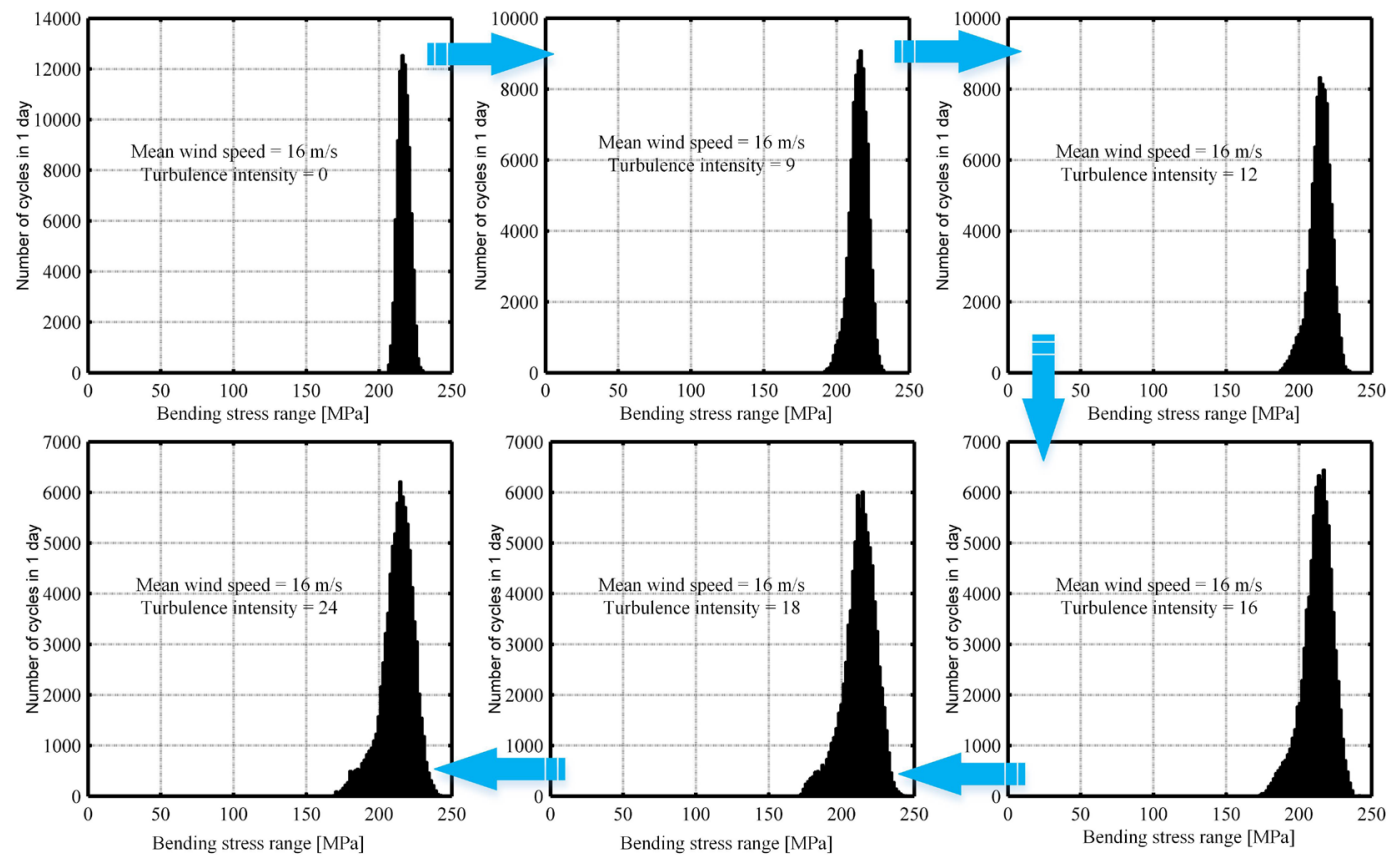

Fig. 13. Bending stress bins of the first stage sun gear when mean wind speed is $16 \mathrm{~m} / \mathrm{s}$ and turbulence intensity ranges from $0 \%$ to $24 \%$ 

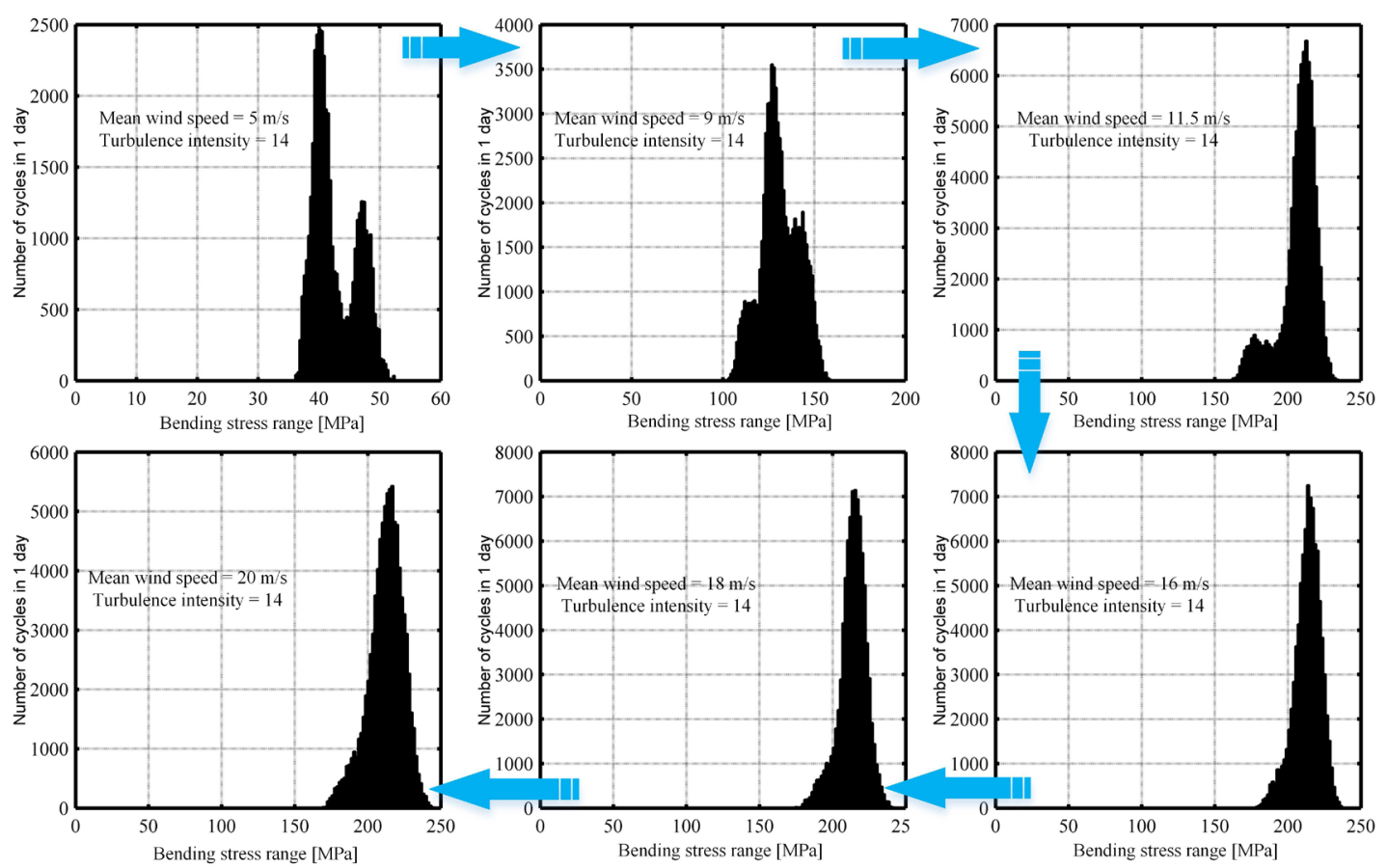

Fig. 14. Bending stress bins of the first stage sun gear when turbulence intensity equals $14 \%$ and mean wind speed ranges from $5 \mathrm{~m} / \mathrm{s}$ to $20 \mathrm{~m} / \mathrm{s}$

than the forward because of the ring gear's large radius of relative curvature; therefore, it is reasonable to only consider the forward pitting fatigue damage.

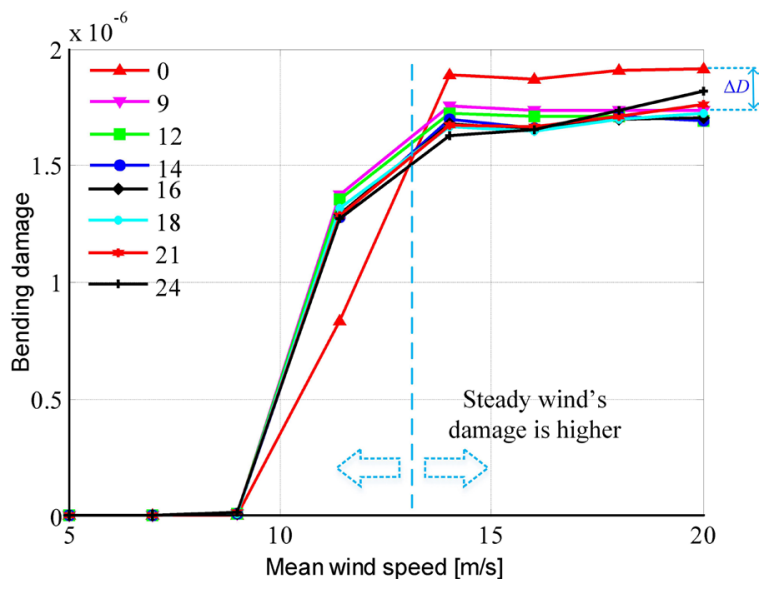

Fig. 15 The influence of mean wind speed on first stage sun gear's bending fatigue damage

\subsection{Fatigue Damage Analysis under Different Wind Loads}

From previous analysis, it can be known that it is reasonable to use only the NTM wind model to study the effect of quasi-steady wind loads on a gearbox's fatigue damage, so that a wind field generated using
NTM wind model with different mean wind speeds and turbulence intensities are applied to the wind turbine, and the dynamic responses are acquired. In this section, the stress bins calculated from gearbox dynamic responses using the LDD method are first analysed to see the influence of quasi-steady wind loads on stress bins' distribution. Then, the fatigue damage under different wind loads was analysed to study the influence of mean wind speed and turbulence intensity. Finally, the sensitivities of the gears' fatigue damage to mean wind speed and turbulence intensity were calculated to find the condition in which mean wind speed and turbulence intensity has a great impact on gears' fatigue damage.

\subsubsection{Stress Bins}

A mechanical component's fatigue damage is calculated from stress bins and SN curve. For a specific gear, the SN curve is determined and stress bins are the only factor influencing component's fatigue damage. Therefore, it is important to study the influence of wind loads on stress bins' distribution.

Fig. 12 shows the first stage sun gear's bending stress bins when mean wind speed equals $7 \mathrm{~m} / \mathrm{s}$ and turbulence intensity ranges from $0 \%$ to $24 \%$ (only bending stress bins are listed since contacting stress 
bins look the same and only 6 turbulence intensities are listed because of limited space). When the wind speed is constant, bending stress bins' distribution is concentrated in $80 \mathrm{MPa}$, and as the wind becomes more turbulent, the stress bins are distributed more dispersedly. When turbulence intensity equals 9 and 12 , the distributions have two concentrations at $80 \mathrm{MPa}$ and $90 \mathrm{MPa}$, and as the intensity increases, another concentration at $70 \mathrm{MPa}$ is forming. It can also be seen that the concentration is moving towards the periphery.

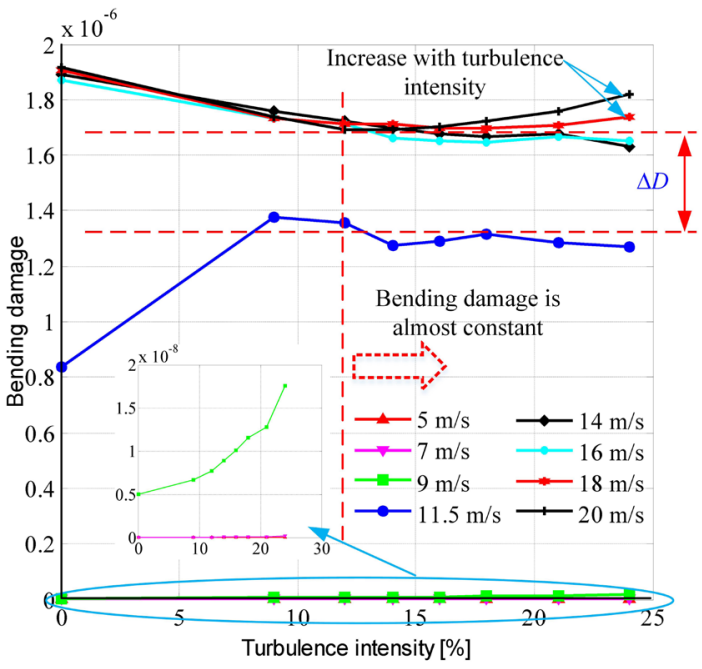

Fig. 16. The influence of turbulence on first stage sun gear's bending fatigue damage

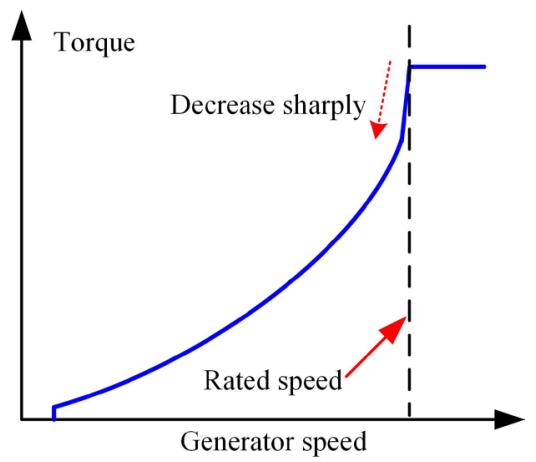

Fig. 17. Generator torque controller

Fig. 13 shows the first stage sun's bending stress bins when the mean wind speed is $16 \mathrm{~m} / \mathrm{s}$ and turbulence intensity ranges from $0 \%$ to $24 \%$. All the stress bins' distributions look similar, which is concentrated at $220 \mathrm{MPa}$, but the stress bins are distributed in a more dispersed manner as turbulence intensity increases. Stress distributes $200 \mathrm{MPa}$ to 225 $\mathrm{MPa}$ when wind speed is constant, while $190 \mathrm{MPa}$ to $230 \mathrm{MPa}$ when the intensity is $9 \%, 180 \mathrm{MPa}$ to
$230 \mathrm{MPa}$ when the intensity is $12 \%, 175 \mathrm{MPa}$ to 235 MPa when the intensity is $16 \%, 170 \mathrm{MPa}$ to $240 \mathrm{MPa}$ when the intensity is $18 \%$ and $150 \mathrm{MPa}$ to $250 \mathrm{MPa}$ when the intensity is $24 \%$. The difference between Fig. 12 and Fig. 13 says that turbulence intensity has a great influence on stress bins' distribution when the mean wind speed is below the rated wind speed, while affect the distribution slightly if mean wind speed is beyond the rated wind speed.

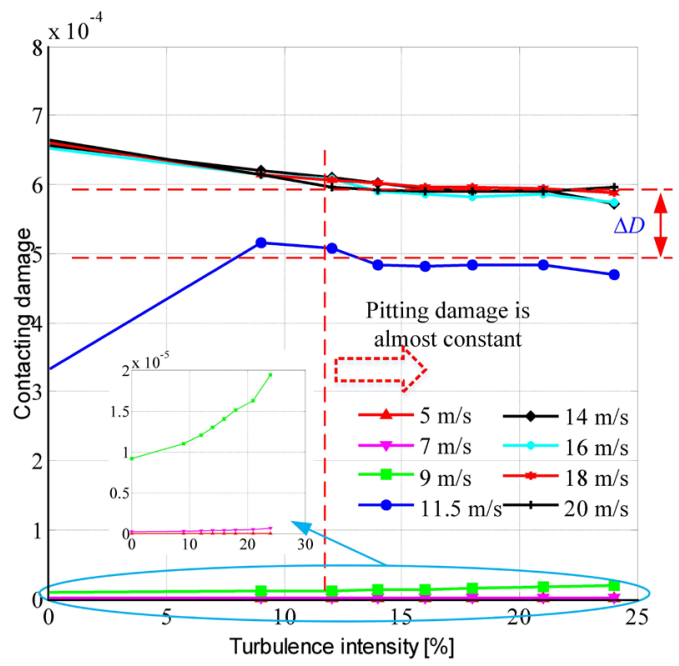

Fig. 18. The influence of turbulence on first stage sun gear's contacting fatigue damage

Fig. 14 shows the stress bins' distribution when the turbulence intensity is $14 \%$ and mean wind speed ranges from $5 \mathrm{~m} / \mathrm{s}$ to $20 \mathrm{~m} / \mathrm{s}$. As the mean wind speed increases, bending stress is increasing the when mean wind speed is below the rated wind speed and is almost the same when beyond. It can also be observed that as the speed increases, stress bins are becoming more concentrated, or in other words, turbulence's influence is decreasing. This is because when wind speed is beyond rated, pitch control starts to work so that the wind speed's variations can be tolerated by the pitch control which results in the decreasing effect of turbulence. When the wind speed is below rated, pitch angle stays at a constant value, and only generator speed is controlled the wind turbulence cannot be tolerated and this would cause bigger contact force variations.

\subsubsection{Mean Wind Speed and Turbulence Intensity's Influence on Gears' Fatigue Damage}

Mean wind speed and turbulence intensity are the two parameters determining wind speed's distribution. Both these parameters' influence on gears' fatigue 
damage are described in this part. First, the first stage sun gear's fatigue damage under different mean wind speeds and turbulence intensities were compared to determine how they affect gearbox's fatigue damage. Second, based on the fatigue damage result, the comparison factors were calculated according to Eq. to find the gear most sensitive to wind loads.

\subsubsection{Influence of Mean Wind Speed and Turbulence Intensity on Gears' Fatigue Damage}

The first stage sun gear's bending damage is shown in Figs. 15 and 16. Both figures contain the same data, $x$-axis in Fig. 15 is mean wind speed which can indicate the influence of mean wind speed on gear's bending fatigue damage, while $x$-axis in Fig. 16 is turbulence intensity which is intended to show the influence of turbulence. From Fig. 15, it is clear that when the mean wind speed is below the rated wind speed, fatigue damage is almost negligible compared with speed equal or beyond. As mean wind speed increases, bending damage also increases and stays almost constant when mean wind speed is larger than $14 \mathrm{~m} / \mathrm{s}$; the result proposed by Nejad et al. [9] also shows the same trend.

Fig. 15 also shows that when the mean wind speed reaches a certain value (maybe between 11.5 $\mathrm{m} / \mathrm{s}$ and $14 \mathrm{~m} / \mathrm{s}$ ), steady wind causes higher damage than turbulent wind; this result is very interesting since in normal aspect, turbulent wind load is considered to be more dangerous. When mean wind speed is larger than $14 \mathrm{~m} / \mathrm{s}$, steady wind causes $\Delta D$ more damage than turbulent wind; this is very interesting because the normal opinion is the turbulent wind is considered to be more dangerous. As the turbulence intensity increases when mean wind speed is higher than $14 \mathrm{~m} / \mathrm{s}$, the stress bins' distribution is becoming more dispersed, and the concentration point is moving slightly towards a smaller value which causes lower fatigue damage.

It can be observed from Fig. 16 that bending fatigue damage increases with turbulence intensity if the mean wind speed is below $11.5 \mathrm{~m} / \mathrm{s}$ (the shape is like a quadratic function), while when turbulence intensity increases higher than $12 \%$, the bending damage for the mean wind speeds equal or beyond the rated wind speed is almost constant (when mean wind speed is $18 \mathrm{~m} / \mathrm{s}$ and $20 \mathrm{~m} / \mathrm{s}$, bending damage shows a rising trend, see Fig. 16). Similar to Fig. 15, after intensity reaches $12 \%$, which means the bending damage is almost constant for high wind speed, there is difference $\Delta D$ between rated wind speed and beyond. This is caused by the generator torque controller (a simple variable-speed controller is used in this paper), the relation between torque and speed is shown in Fig. 17, the generator torque decrease sharply when generator speed is below rated. The rated wind speed of the wind turbine model used in this study may be slightly higher than $11.5 \mathrm{~m} / \mathrm{s}$ (possibly $11.6 \mathrm{~m} / \mathrm{s}$ ), so that generator speed is slightly below rated when the mean wind speed equals $11.5 \mathrm{~m} / \mathrm{s}$ which results in a lower torque on the main shaft.

The first stage sun gear's contacting fatigue damage is shown in Fig. 18, it is almost the same as Fig. 16 since they use the same force bins. Fig. 18 is listed here to show that fatigue damage does not show a rising trend when mean wind speed is equal or beyond $18 \mathrm{~m} / \mathrm{s}$, which says that the rising trend observed in the first stage sun gear's bending damage is not general.

\subsubsection{Fatigue Damage Comparison Factor}

From the result of section 2.1, vulnerable gears with the highest pitting or bending fatigue damage among each stage were found. To see the influence of quasisteady wind loads on every vulnerable gear's fatigue damage clearly, the fatigue damage is also presented as a percentage compared to the damage when the constant, rated wind speed is loaded. The percentage, $\eta$, is defined as:

$$
\eta=\frac{D-D_{\text {constant, }, \text { rated }}}{D_{\text {constant, } \text {,rated }}} \times 100,
$$

where $D_{\text {constant,rated }}$ and $D$ are the fatigue damage when constant rated wind and other winds are loaded, respectively. From the value of $\eta$, the influence of mean wind speed and turbulence intensity can be known easily that negative $\eta$ indicates less damage while positive means more.

The fatigue damage comparison factors of each gear were calculated, which is shown in Table 7. The data in the table tells how gears' fatigue damages change with wind loads, and higher values indicate that the corresponding gear's fatigue damage changes more severely as wind field changes.

There are four types of numbers in the table, dashed underline, single underline, boxed and shadowed. The values with dashed underlined indicate lower damage (only one row is listed for mean wind speed lower than rated for simplicity), the shadowed values imply comparison factors ranging from $60 \%$ to $80 \%$, the boxed values are within $80 \%$ to $100 \%$, and the values with single-line are beyond $100 \%$. 
Table 7. Fatigue damage comparison factor

\begin{tabular}{|c|c|c|c|c|c|c|c|}
\hline \multirow{2}{*}{ 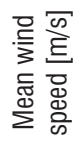 } & \multirow{2}{*}{ 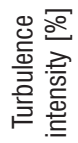 } & \multicolumn{3}{|c|}{ Bending damage } & \multicolumn{3}{|c|}{ Contacting damage } \\
\hline & & r1 & r2 & p3 & s1 & s2 & p3 \\
\hline 9 & 24 & -94.4 & -94.8 & -99.6 & -94.1 & $=9 \underline{9} .9$ & $=\underline{9} \underline{\underline{8} .5}$ \\
\hline \multirow{8}{*}{11.5} & 0 & 0 & 0 & 0 & 0 & 0 & 0 \\
\hline & 9 & 54.9 & 39.2 & 30.4 & 54.9 & 34.9 & 31.3 \\
\hline & 12 & 52.7 & 37 & 51.1 & 53 & 34 & 45.8 \\
\hline & 14 & 44.9 & 30.9 & 27.4 & 45.2 & 27.2 & 30 \\
\hline & 16 & 44.8 & 32.4 & 31.6 & 44.8 & 29.4 & 29.4 \\
\hline & 18 & 45.6 & 34 & 18 & 45.5 & 30.1 & 16.7 \\
\hline & 21 & 45.3 & 32.8 & 44.2 & 45.5 & 29.1 & 38.8 \\
\hline & 24 & 41.4 & 28.6 & 31 & 41.3 & 25.1 & 28.4 \\
\hline \multirow{8}{*}{14} & 0 & 97.7 & 82.4 & 102.2 & 97.3 & 81.9 & 89 \\
\hline & 9 & 86.9 & $\underline{67.2}$ & $\underline{66.3}$ & 86.7 & $\underline{66.2}$ & $\underline{61.3}$ \\
\hline & 12 & 83.9 & $\underline{65.4}$ & $\underline{79}$ & 83.8 & $\underline{62.8}$ & 88.4 \\
\hline & 14 & 81.1 & $\underline{61.8}$ & 87 & 81 & 58.7 & $\underline{76.1}$ \\
\hline & 16 & $\underline{79.1}$ & $\underline{61.7}$ & 91.9 & $\underline{78.8}$ & 58.2 & $\underline{74.2}$ \\
\hline & 18 & $\underline{77.7}$ & $\underline{62.3}$ & $\underline{73.1}$ & $\underline{77.3}$ & 59.1 & $\underline{64.5}$ \\
\hline & 21 & $\underline{78.4}$ & $\underline{60.7}$ & $\underline{74.3}$ & $\underline{78.2}$ & 58.9 & $\underline{65.7}$ \\
\hline & 24 & $\underline{72.5}$ & 57.1 & 102 & $\underline{72.3}$ & 54.4 & 75.3 \\
\hline \multirow{8}{*}{16} & 0 & 971 & \begin{tabular}{|l|}
95.5 \\
\end{tabular} & $\underline{203.5}$ & 96.4 & 102.8 & 151.1 \\
\hline & 9 & \begin{tabular}{|l|}
85 \\
\end{tabular} & $\underline{66}$ & 80.1 & 84.7 & $\underline{63.4}$ & $\underline{69.2}$ \\
\hline & 12 & 82.7 & $\underline{64.4}$ & \begin{tabular}{|l|}
97.3 \\
\end{tabular} & 82.7 & $\underline{62.3}$ & $\underline{79.9}$ \\
\hline & 14 & $\underline{77.9}$ & 59.7 & 114.2 & $\underline{77.7}$ & 57.6 & 87.9 \\
\hline & 16 & 76.2 & 56.6 & $\underline{67}$ & 76.2 & 53.8 & 57.1 \\
\hline & 18 & $\underline{75.4}$ & 58.4 & 107.6 & $\underline{75.1}$ & 55 & 85.7 \\
\hline & 21 & 76.9 & 56.4 & 101.6 & $\underline{76.6}$ & 54.1 & $\underline{78.4}$ \\
\hline & 24 & $\underline{73.3}$ & 55.8 & 126.4 & $\underline{72.6}$ & 53.3 & 91.5 \\
\hline \multirow{8}{*}{18} & 0 & 99.2 & 82.9 & 143.8 & 98.9 & 82.3 & 115.3 \\
\hline & 9 & \begin{tabular}{|l|}
85 \\
\end{tabular} & $\underline{69.3}$ & 107.4 & 84.8 & $\underline{67.9}$ & 83.9 \\
\hline & 12 & 82.5 & $\underline{65.6}$ & \begin{tabular}{|l|}
80.8 \\
\end{tabular} & 82.2 & $\underline{62.1}$ & $\underline{65.8}$ \\
\hline & 14 & 81.5 & $\underline{62.5}$ & 104.1 & 81.4 & $\underline{60.1}$ & $\underline{78.6}$ \\
\hline & 16 & \begin{tabular}{|l|}
80 \\
\end{tabular} & 58.2 & \begin{tabular}{|l|}
99 \\
\end{tabular} & $\underline{79.6}$ & 54.7 & $\underline{77.3}$ \\
\hline & 18 & 79.4 & 59.3 & 105.3 & 79.2 & 56.9 & 81.6 \\
\hline & 21 & $\underline{79}$ & $\underline{60.7}$ & 125.8 & $\underline{78.5}$ & 58.7 & \begin{tabular}{|l|}
97.5 \\
\end{tabular} \\
\hline & 24 & $\underline{77.7}$ & 57.6 & 195.5 & $\underline{77.1}$ & 56.7 & 135.4 \\
\hline \multirow{8}{*}{20} & 0 & 100 & $\underline{75}$ & 118.3 & 99.8 & $\underline{75.6}$ & 95 \\
\hline & 9 & \begin{tabular}{|l|}
84.9 \\
\end{tabular} & $\underline{61.3}$ & 104.5 & \begin{tabular}{|l|}
84.8 \\
\end{tabular} & $\underline{60.2}$ & $\underline{78.1}$ \\
\hline & 12 & 79.4 & 56.3 & 114.8 & 79.3 & 54.8 & 89.8 \\
\hline & 14 & $\underline{78.6}$ & 59.2 & 152.1 & $\underline{78}$ & 57.5 & 112.9 \\
\hline & 16 & $\underline{78.1}$ & 54.8 & 136.2 & $\underline{77.7}$ & 53.4 & 94.7 \\
\hline & 18 & 88.4 & 56.7 & 181.2 & $\underline{77.7}$ & 55.3 & 117.5 \\
\hline & 21 & $\underline{78.4}$ & $\underline{61.7}$ & 192.3 & $\underline{77.8}$ & $\underline{61.2}$ & 120 \\
\hline & 24 & $\underline{79.9}$ & $\underline{60.4}$ & 296.8 & $\underline{79.3}$ & 58.3 & 166 \\
\hline
\end{tabular}

The first impression of the result is that all the values with dashed-line are very close to -100 , which means fatigue damage is almost neglectable. Another impression is that almost all the shadowed values are third stage pinion's bending and pitting fatigue damage, especially bending fatigue damage. This implies that the third stage's pinion is the component most sensitive to wind loads among the chosen components. It can also be observed that most of the boxed values are first stage ring gear's bending and sun gear's pitting fatigue damage, while most of the second stage ring gear's bending and sun gear's pitting comparison factors are values with a singleline or without an underline. A wind sensitivity map can be derived, which indicates the ranking of gears' fatigue damage sensitivity to wind loads, shown in Table 8. Details about gears' sensitivity to wind load will be discussed in section 2.2.3.

The results of this part are very useful in practice, the gear with higher sensitivity to wind loads needs more concern (for example it should be designed with higher reliability) when designing since wind loads have a greater impact on gear's fatigue damage, and this would cause gear's fatigue damage to become more uncertain because of wind loads' uncertainties.

\subsubsection{Gears' Fatigue Damage Sensitivity to Mean Wind Speed and Turbulence Intensity}

In section 2.2.2.2, the chosen components' sensitivity is divided into three levels by comparing their fatigue damage comparison factors. In this section, details about gears' sensitivity to mean wind speed and turbulence intensity will be discussed.

First-order partial derivatives are used to describe damage sensitivity, $\partial D / \partial V$ and $\partial D / \partial I$ are used to describe sensitivities to mean wind speed and turbulence intensity, respectively. To improve the result's visibility, spline interpolation is used. The first stage sun gear' contacting fatigue damage sensitivity to mean wind speed and turbulence intensity is shown in Figs. 19 and 20, respectively. Other components' fatigue damage sensitivities show little difference.

Table 8. Levels of gears' fatigue damage sensitivity to wind loads

\begin{tabular}{ll}
\hline Level & fatigue damage \\
\hline \multirow{2}{*}{ Level-1 } & $3^{\text {rd }}$ stage pinion's bending \\
\cline { 2 - 2 } Level-2 & $3^{\text {rd }}$ stage pinion's contacting \\
\cline { 2 - 2 } & $1^{\text {st }}$ stage ring gear's bending \\
\hline Level-3 & $2^{\text {nd }}$ stage ring gear's contacting \\
\cline { 2 - 2 } & $2^{\text {nd }}$ stage sun gear's contacting \\
\hline
\end{tabular}

As Fig. 19 shows, sensitivity to mean wind speed (sensitivity to speed will be used in the following for simplicity) is positive for almost all wind fields. It can also be observed that sensitivity to speed does not change as turbulence intensity changes. The sectional 
view in Fig. 19 shows that as speed decreases, sensitivity to speed has the peak value at mean wind speed $11.5 \mathrm{~m} / \mathrm{s}$ and speed below $7.9 \mathrm{~m} / \mathrm{s}$. This implies that the first stage sun gear's contacting fatigue damage is more sensitive to mean wind speed when wind speed is very low or at the rated wind speed in comparison with other cases.

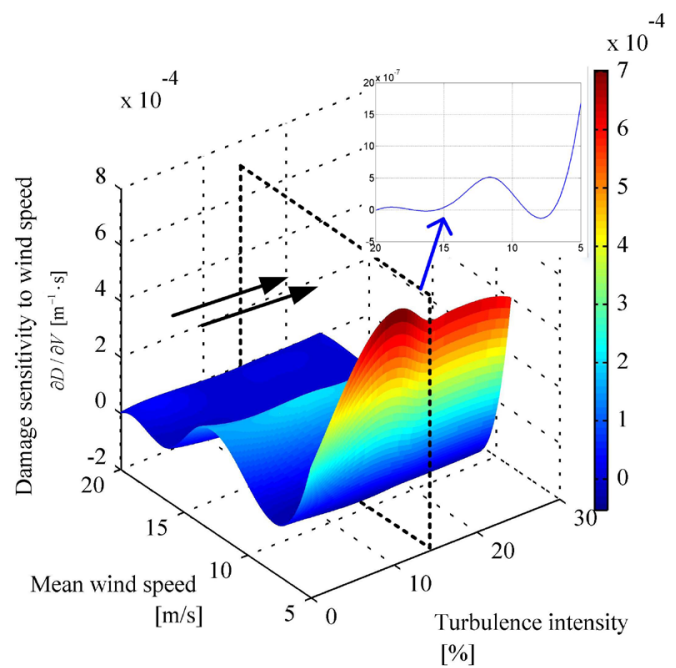

Fig. 19. First stage sun gear's contacting fatigue damage's sensitivity to mean wind speed

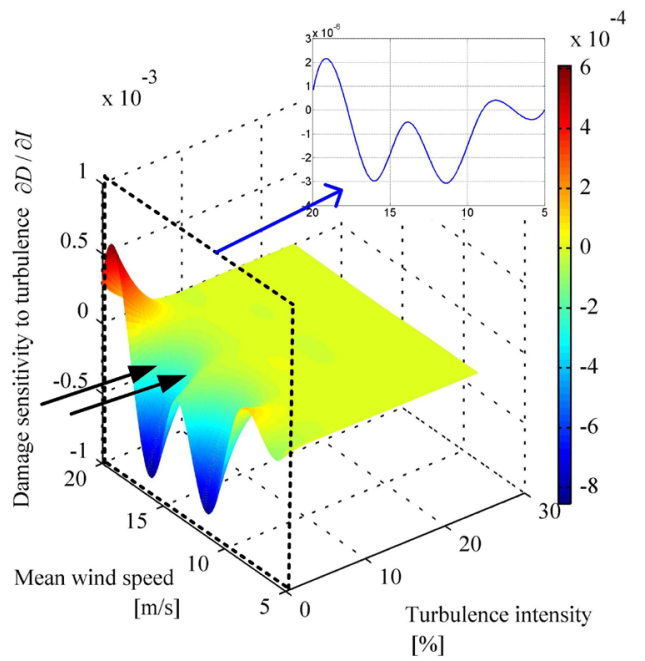

Fig. 20. First stage sun gear's contacting fatigue damage's sensitivity to turbulence intensity

Fig. 20 shows sensitivity to turbulence intensity, and the first impression is that when turbulence is beyond $9 \%$, sensitivity to turbulence is almost zero, which means turbulence has little influence on contacting fatigue damage. This is caused by the small fatigue damage value for low wind speeds. While for high wind speeds, observed from Fig. 18, it is because the turbulence has little influence on fatigue damage when turbulence intensity is greater than $12 \%$.

Fig. 20 also shows that when turbulence intensity is lower than $9 \%$, damage sensitivity varies greatly for high wind speeds. There are two valleys (negative) at speed $11.5 \mathrm{~m} / \mathrm{s}$ and $16 \mathrm{~m} / \mathrm{s}$, which means that as the wind becomes more turbulent, fatigue damage would decrease. When mean speed is higher than $17 \mathrm{~m} / \mathrm{s}$, sensitivity to turbulence becomes positive and has the peak value at mean wind speed $19 \mathrm{~m} / \mathrm{s}$ which means fatigue damage increases with turbulence.

Gears' sensitivity to wind loads is useful when designing a pitch control system. At some sensitive points, the pitch control system should be able to tolerate the variation of the wind loads since at these points gears' fatigue damage varies significantly as wind speed changes.

\section{CONCLUSIONS}

The influence of quasi-steady wind loads on wind turbine gearbox's fatigue life was studied, and the following conclusions about the influence can be drawn:

1. The vulnerable components of each stage are found based on their pitting and bending fatigue damage. This is useful for detecting the source of fault. The first and second stage's ring gear and third stage's pinion are found to be the vulnerable components considering bending fatigue. The first and second stage's sun gear and third stage's pinion were found to be the components with highest probability of pitting failure.

2. Fatigue damage is found to be almost constant when mean wind speed is higher than $14 \mathrm{~m} / \mathrm{s}$ or when turbulence intensity is beyond $14 \%$ with mean wind speed higher than rated, in other word, wind loads will not cause more fatigue damage. This is a very important conclusion since it implies that it is not the quasi-steady wind loads that accelerate the gearbox's failure. This is caused by the fast response of the pitch control system, which can tolerate wind speed's variance.

3. As the mean wind speed increases beyond 13 $\mathrm{m} / \mathrm{s}$, the fatigue damage caused by steady wind is higher than turbulent winds. This is interesting since in normal opinion, turbulent wind is more dangerous. While when mean wind speed is below rated, the fatigue damage increases with turbulence intensity, but the damage caused by mean wind speed below rated is almost neglectable compared with beyond. 
4. From the vulnerable gears' damage comparison factor table, the third stage's pinion is found to be the component most sensitive to wind loads. This is meaningful when designing gearboxes, since the sensitive gear requires more concern (for example, it should be designed with higher reliability) because of the great impact of wind loads.

5. Gears' fatigue damage sensitivity to wind speed was found to be constant with turbulence intensity and has the peak value when the mean wind speed equals rated or very low (below $7 \mathrm{~m} / \mathrm{s}$ ). At these positive sensitivity points, especially the peak, pitch control system should be designed to be able to tolerate the variation of wind speed.

\section{ACKNOWLEDGEMENTS}

The authors gratefully acknowledge the support of the China National Science Foundation project "Study on energy space distribution characteristics and its influence on fatigue crack growth mechanism of wind turbine gearbox" (project number 51475263).

\section{REFERENCES}

[1] Musial, W., Butterfield, S., Mcniff, B. (2007). Improving Wind Turbine Gearbox Reliability. European Wind Energy Conference, Milan.

[2] Rosen, A., Sheinman, Y. (1994). The average output power of a wind turbine in a turbulent wind. Journal of Wind Engineering and Industrial Aerodynamics, vol. 51, no. 3, p. 287-302, DOl:10.1016/0167-6105(94)90064-7.

[3] Sheinman, Y., Rosen, A. (1992). A dynamic model of the influence of turbulence on the power output of a wind turbine. Journal of Wind Engineering \& Industrial Aerodynamics, vol. 39, no. 1-3, p. 329-341, D0I:10.1016/0167-6105(92)90557-Q.

[4] Jin, X., Liu, H., Ju, W. (2014). Wind turbine seismic load analysis based on numerical calculation. Strojniški vestnik - Journal of Mechanical Engineering, vol. 60, no. 10, p. 638648, D0I:10.5545/sv-jme.2014.1646.

[5] Nejad, A.R., Bachynski, E.E., Kvittem, M.I., Luan, C., Gao, Z. Moan, T. (2015). Stochastic dynamic load effect and fatigue damage analysis of drivetrains in land-based and TLP, spar and semi-submersible floating wind turbines. Marine Structures, vol. 42, p. 137-153, D0l:10.1016/j.marstruc.2015.03.006.

[6] Oyague, F. (2009). Gearbox modeling and load simulation of a baseline $750-k w$ wind turbine using state-of-the-art simulation codes. Technical Report, National Renewable Energy Laboratory, Golden, Dol:10.2172/947884.

[7] Micallef, D., Sant, T. (2015). Loading effects on floating offshore horizontal axis wind turbines in surge motion. Renewable Energy, vol. 83, p. 737-748, D0l:10.1016/j. renene.2015.05.016.

[8] Nejad, A.R., Xing, Y., Guo, Y., Keller, J., Gao, Z., Moan, T. (2015). Effects of floating sun gear in a wind turbine's planetary gearbox with geometrical imperfections. Wind Energy, vol. 18, no. 12, p. 2105-2120, Dol:10.1002/we.1808.

[9] Nejad, A.R., Gao, Z., Moan, T. (2014). On long-term fatigue damage and reliability analysis of gears under wind loads in offshore wind turbine drivetrains. International Journal of Fatigue, vol. 61, p. 116-128, D0l:10.1016/j. ijfatigue.2013.11.023.

[10] Dong, W., Xing, Y., Moan, T., Gao, Z. (2013). Time domainbased gear contact fatigue analysis of a wind turbine drivetrain under dynamic conditions. International Journal of Fatigue, vol. 48, p. 133-146, D0l:10.1016/j.jfatigue.2012.10.011.

[11] Dong, W., Xing, Y., Moan, T. (2012). Time domain modeling and analysis of dynamic gear contact force in a wind turbine gearbox with respect to fatigue assessment. Energies, vol. 5, no. 11, p. 4350-437, D0l:10.3390/en5114350.

[12] Xu, X., Tao, Y., Liao, C., Dong, S., Chen, R. (2016). Dynamic simulation of wind turbine planetary gear systems with gearbox body flexibility. Strojniški vestnik - Journal of Mechanical Engineering, vol. 62, no. 11, p. 678-684, D0l:10.5545/svjme.2016.3637.

[13] Ajmi, M., Velex, P. (2005). A model for simulating the quasistatic and dynamic behaviour of solid wide-faced spur and helical gears. Mechanism and Machine Theory, vol. 40, no. 2, p. 173-190, D0I:10.1016/J.mechmachtheory.2003.06.001.

[14] Osman, T., Velex, P. (2012). A model for the simulation of the interactions between dynamic tooth loads and contact fatigue in spur gears. Tribology International, vol. 46, no. 1, p. 84-96, D0I:10.1016/j.triboint.2011.03.024.

[15] Kaimal, J.C., Wyngaard, J.C., Izumi, Y., CotéO.R. (1972). Spectral characteristics of surface-layer turbulence. Quarterly Journal of the Royal Meteorological Society, vol. 98, no. 417, p. 563-589, DOl:10.1002/qj.49709841707.

[16] Jonkman, B.J. (2009). TurbSim User's Guide. National Renewable Energy Laboratory, Golden, D0I:10.2172/965520.

[17] IEC 61400-1:2005 (2005). Wind turbines - Part1: Design requirements. International Electrotechnical Commission, Geneva.

[18] Lescher, F., Zhao, J.Y., Borne, P. (2006). Robust gain scheduling controller for pitch regulated variable speed wind turbine. Studies in Informatics \& Control, vol. 14, no. 4, p. 299-315.

[19] Giesbers, J. (2012). Contact Mechanics in MSC Adams - A technical evaluation of the contact models in multibody dynamics software MSC Adams. University of Twente, Twente.

[20] ISO 6336-3:2006(E) (2008). Calculation of load capacity of spur and helical gears - Part 3: Calculation of tooth bending strength. International Organization for Standardization, Geneva.

[21] ISO 6336-2:2006(E) (2006). Calculation of load capacity of spur and helical gears - Part 2: Calculation of surface durability (pitting). International Organization for Standardization, Geneva.

[22] ISO 6336-5:2003(E) (2003). Strength and quality of materials. International Organization for Standardization, Geneva.

[23] Nejad, A.R., Gao, Z., Moan, T. (2014). Fatigue reliability-based inspection and maintenance planning of gearbox components in wind turbine drivetrains. Energy Procedia, vol. 53, p. 248257, D0I:10.1016/j.egypro.2014.07.234. 